\title{
A STUDY ON THE MECHANICAL PROPERTIES OF S45C MEDIUM TYPE CARBON STEEL SPECIMENS UNDER LATHE MACHINING AND QUENCHING CONDITIONS
}

\author{
M. Riaz ${ }^{1}$, N. Atiqah ${ }^{2}$ \\ ${ }^{I}$ Department of Mechanical and Manufacturing Engineering, University Kuala Lumpur Malaysia France Institute, \\ Jalan Teras Jernang, Section 14, Bangi, 43650 Selangor Malaysia \\ ${ }^{2}$ Department of Mechanical and Manufacturing Engineering, University Kuala Lumpur Malaysia France Institute, \\ Jalan Teras Jernang, Section 14, Bangi, 43650 Selangor Malaysia
}

\begin{abstract}
The experimental process is a fundamental technique used to determine the nature and behavior of many materials under study. In order to evaluate the fundamental properties of many engineering materials the use of mechanical testing techniques frequently play a crucial role. The development of new materials and the control of material quality are essential in the process of design and in their usage for industrial applications and construction. In this experiment, there were 2 sets (5 samples each) of medium type steel specimens S45C of $0.45 \%$ carbon content that were rigorously prepared according to ASTM standards under specific varied parameters. These parameters include the machining cutter speeds on the lathe machine and the mediums selected and temperatures set for the quenching process on the steel specimens in order to affect their overall microstructure. The specimens were then subjected to aggregate mechanical loading using a conventional tensile testing machine. The consequential effect of material structure metamorphosis under the selected quenching techniques was ultimately not part of the study as it involves microscopic analysis of grain boundaries and high-end precision equipment would be necessary to do any significant material analysis. The results of the experiment suggest that the macroscopic (not microscopic) effect of the lathe machining speeds do not significantly affect the tensile material strength of the S45 medium carbon steel specimen. Thus, the mediums and temperatures selected for the quenching process on the specimens had a marginal but significant effect on the elevated levels of tensile mechanical strength and strain of medium type carbon steel.
\end{abstract}

Keywords: mechanical properties, carbon steel, lathe machine, S45C, quenching process, tensile test, stress, strain. $* * *$

\section{INTRODUCTION}

The importance of tensile testing in relation to mechanical material properties is fundamental and rudimentary for most applications. The nature of experimentation would hinge on details such as the material used, the size of the tensile specimen, the type of cutting tools used, the machining cutter speed, the type of milling machine and the medium of quenching employed on the specimen.

\subsection{Medium Carbon Steel S45C}

In most industrial manufacturing applications, plain carbon steels are widely used because of their low cost and ease of fabrication (Smith and Hashemi 2006) ${ }^{[1]}$. They are classified on the basis of their carbon content as their major alloying element is carbon. The carbon content of high carbon steels normally range above $0.65 \%$. Medium carbon steels can be heat treated to have a good balance of ductility and strength. Hardness and other mechanical properties of plain carbon steels typically increase when the content of carbon dissolved in the austenite phase prior to quenching during hardening and heat treatment (Anand B. Deshpande, 2010) ${ }^{[3]}$ is transformed from austenite into martensite (Feng and Tahir, 2008) ${ }^{[4]}$. (Grishin and Huryukin 1996; Kulikov 1997; Tolstousov and Bannykh 1999) ${ }^{[5] .}$ 


\section{Chemical composition}

\begin{tabular}{|c|c|c|c|c|c|c|c|c|c|c|c|c|c|}
\hline \multirow{2}{*}{ Classification } & \multicolumn{2}{|c|}{ Designation } & \multicolumn{11}{|c|}{ Chemical composition (\%) } \\
\hline & JIS & SAE & $\mathrm{C}$ & $\mathrm{Si}$ & $\mathrm{Mn}$ & $P$ & S & $\mathrm{Cu}$ & $\mathrm{Ni}$ & $\mathrm{Cr}$ & $\mathrm{Ni}+\mathrm{Cr}$ & Mo & V \\
\hline \multirow{15}{*}{ Carbon steel } & $\mathrm{S} 20 \mathrm{C}$ & & $0.18-0.23$ & $0.15-0.35$ & $0.30-0.60$ & $\leq 0.030$ & $\leq 0.035$ & $\leq 0.30$ & $\leq 0.20$ & $\leq 0.20$ & $\leq 0.35$ & & \\
\hline & S35C(M) & & $0.32-0.38$ & $0.15-0.35$ & $0.60-0.80$ & $\leq 0.030$ & $\leq 0.035$ & $\leq 0.30$ & $\leq 0.20$ & $\leq 0.20$ & $\leq 0.35$ & & \\
\hline & $S 45 C(M)$ & & $0.42-0.48$ & $0.15-0.35$ & $0.60-0.90$ & $\leq 0.030$ & $\leq 0.035$ & $\leq 0.30$ & $\leq 0.20$ & $\leq 0.20$ & $\leq 0.36$ & & \\
\hline & S50C(M) & & $0.47-0.63$ & $0.15-0.35$ & $0.60-0.80$ & $\leq 0.030$ & $\leq 0.035$ & $\leq 0.30$ & $\leq 0.20$ & $\leq 0.20$ & $\leq 0.35$ & & \\
\hline & & SAE1050 & $0.48-0.55$ & $0.15-0.35$ & $0.60-0.80$ & $\leq 0.030$ & $\leq 0.050$ & & & & & & \\
\hline & S55C(M) & & $0.62-0.68$ & $0.15-0.35$ & $0.60-0.80$ & $\leq 0.030$ & $\leq 0.035$ & $\leq 0.30$ & $\leq 0.20$ & $\leq 0.20$ & $\leq 0.36$ & & \\
\hline & & SAE1055 & $0.60-0.60$ & $0.15-0.35$ & $0.60-0.80$ & $\leq 0.030$ & $\leq 0.050$ & & & & & & \\
\hline & $\mathrm{S} 60 \mathrm{CM}$ & & $0.55-0.65$ & $0.15-0.35$ & $0.60-0.80$ & $\leq 0.030$ & $\leq 0.035$ & $\leq 0.30$ & $\leq 0.20$ & $\leq 0.20$ & & & \\
\hline & & SAE1060 & $0.65-0.65$ & $0.15-0.35$ & $0.60-0.80$ & $\leq 0.030$ & $\leq 0.050$ & & & & & & \\
\hline & $\mathrm{S} 65 \mathrm{CM}$ & & $0.60-0.70$ & $0.15-0.35$ & $0.60-0.80$ & $\leq 0.030$ & $\leq 0.035$ & $\leq 0.30$ & $\leq 0.20$ & $\leq 0.20$ & & & \\
\hline & & SAE1065 & $0.60-0.70$ & $0.15-0.35$ & $0.60-0.80$ & $\leq 0.030$ & $\leq 0.050$ & & & & & & \\
\hline & S70CM & & $0.65-0.75$ & $0.15-0.35$ & $0.60-0.90$ & $\leq 0.030$ & $\leq 0.035$ & $\leq 0.30$ & $\leq 0.20$ & $\leq 0.20$ & & & \\
\hline & & SAE1070 & $0.65-0.75$ & $0.15-0.35$ & $0.60-0.80$ & $\leq 0.030$ & $\leq 0.050$ & & & & & & \\
\hline & & SAE1074 & $0.70-0.80$ & $0.15-0.35$ & $0.60-0.80$ & $\leq 0.030$ & $\leq 0.050$ & & & & & & \\
\hline & S75CM & & $0.70-0.80$ & $0.15-0.35$ & $0.60-0.90$ & $\leq 0.030$ & $\leq 0.035$ & $\leq 0.30$ & $\leq 0.20$ & $\leq 0.20$ & & & \\
\hline
\end{tabular}

Fig 1: Chemical composition of carbon steel (S45C)

\subsection{Tensile Testing}

The tensile properties of a material are indicative of how the material will react while being subjected to forces in tension. The tensile test is a fundamental mechanical test where a carefully prepared specimen is loaded in a controlled environment or mechanism while measuring the applied load and the elongation of the specimen over some predetermined distance. Among the more common parameters available for measurement during tensile testing include the modulus of elasticity, elastic limit, elongation, proportional limit, reduction in cross-sectional area, tensile strength, yield point, and yield strength. A tensile specimen is a standardized sample of cross-section with two shoulders and a gauge (section) in between them that are larger so that it can readily gripped, whereas the gauge section has a smaller cross-section so that the deformation and failure can occur in that predetermined area.

Tensile tests are performed for several reasons. The results of tensile tests can be used in the selection of materials for engineering applications and design, to enhance quality, or even to predict the behavior of a material under specific forms of loading other than uniaxial tension. The strength of a material is often of primary concern, measured in terms of either the stress necessary to cause appreciable plastic deformation or the maximum quantum of stress that the material can withstand.

Also of interest is the material's ductility, which is a measure of how much it can be deformed before it fractures. Ductility is directly incorporated into design and material specification to ensure quality and toughness. The fracture of a material measures how much of a load a material can take before it breaks when it is in the process of being stretched for low ductility in a tensile test and is often accompanied by low resistance (Yunkai Lu, 2002) ${ }^{[6]}$. In Figure 2 the graph shows the strain versus stress relationship under tensile loading of a typical medium carbon steel specimen at normal length before tensile test until the specimen fractures or breaks. 


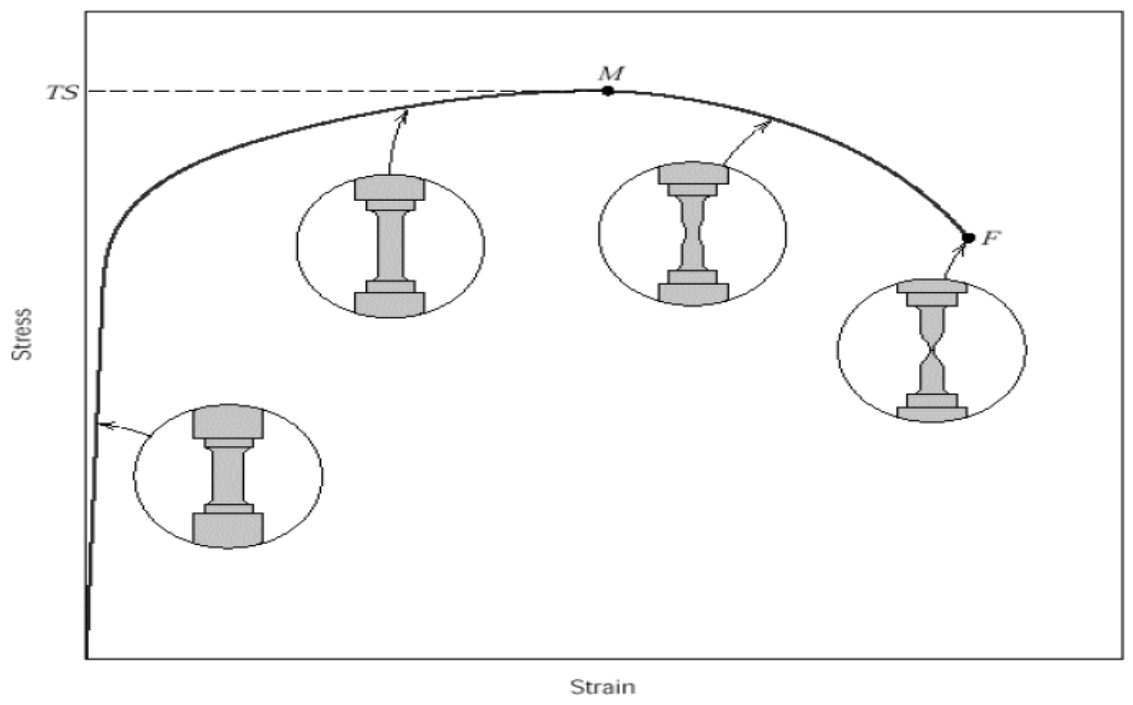

Fig 2: Strain versus stress under tensile testing

\subsection{Tensile Testing Machine and Test Specimen}

A testing machine (see Figure 3) also known as a universal tester, materials testing machine or materials test frame, is frequently used to test the tensile test and compressive strength of materials. It is named after the fact that it can perform many standard tensile and compression tests on materials, components, and structures. The set-up and usage of the machine is often detailed in a procedure that outlines sample preparation, fixturing, gauge length (the length which is under study or observation), analysis, etc. The specimen is placed in the machine between the grips and an extensometer (if required) can automatically record the change in gauge length during the test. If an extensometer is not fitted, the machine itself can record the displacement between its cross heads on which the specimen is held. However, this method not only records the change in length of the specimen but also all other extending or resulting elastic components of the testing machine and its drive systems, including any slipping of the specimen in the grips. Once the machine is started it begins to apply an increasing amount of load on the specimen. Throughout the tests the control system and its associated software record the load and extension (or compression) of the specimen. Machines of similar type and function range from very small table top systems to ones that can enforce loading capacity in the range of $53,000 \mathrm{kN}$.

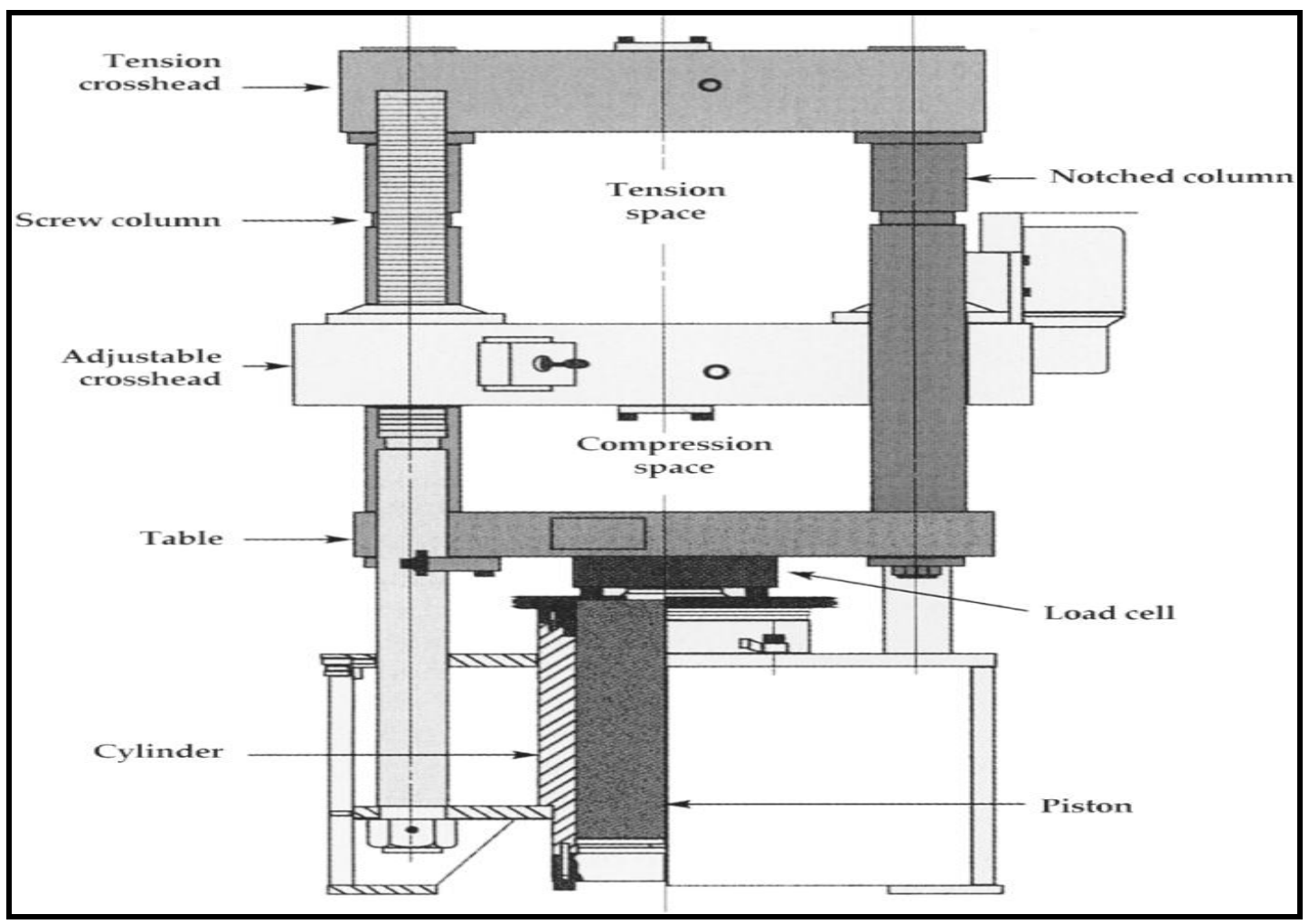

Fig 3: Tensile Testing Machine 
In Figure 4, a cross section of a test sample specimen is shown, emphasizing the limited flexibility of the machine to test objects that do not follow standardized dimensions. The alphanumeric designated dimensions can be found in the respective machine's standardized manuals for sample preparation.

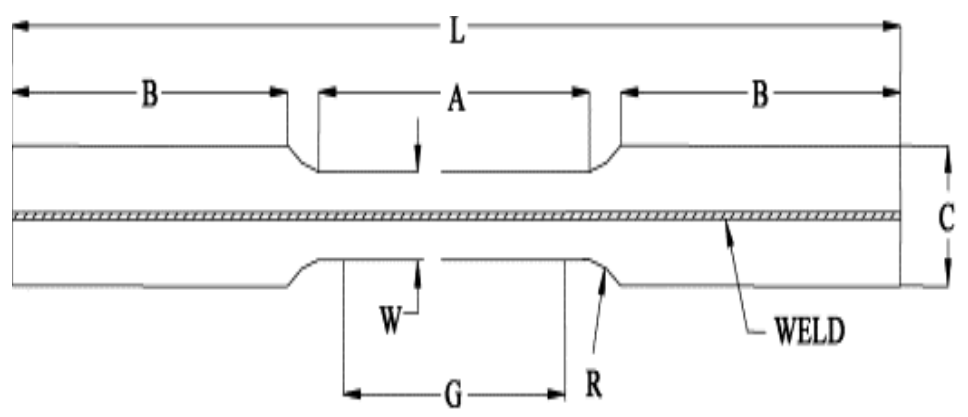

Fig 4: Test Specimen

\section{EXPERIMENTAL SETUP AND PROCEDURES}

In the experiment, the tensile test specimens are initially fabricated using the RAMO 33 conventional lathe machine and later tested using the VEW 2302 universal tensile test machine. The specimens were fabricated using the ASTM E8 standard for metallic materials. Arrays of specific parameters were carefully selected for mediums of quenching, heat treatments and tensile testing.

The drawing of the tensile test specimens was prepared using the CATIA ${ }^{\circledR}$ (V5R16) software to avoid any occurrences of error during the machining process and to adopt distinct levels of accuracy for the specified length and diameter of $200 \mathrm{~mm}$ and $20 \mathrm{~mm}$ respectively. The shape shown is commonly referred to as the rod/dumbbell type shaped specimen.

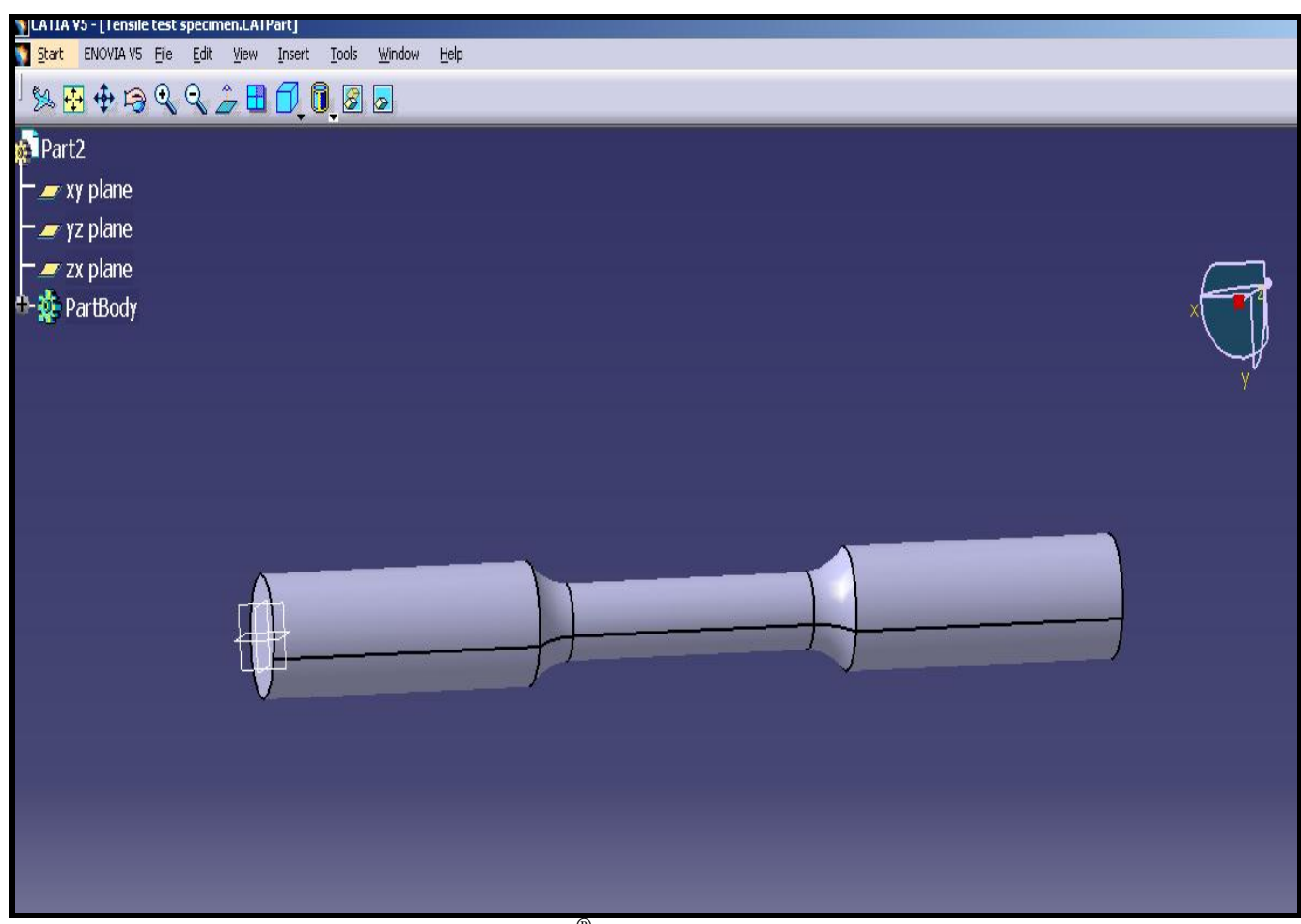

CATIA $^{\circledR}$ (V5R16) software

The material selected for the fabrication of the 10 sample test specimens was medium type carbon steel S45 (refer to Figure 1 for composition range) since it is widely used and available in industry. The lathe process (see Figure 5) were run constant cutting speed of 430 RPM and 860 RPM respectively using the WIDIA uncoated micro grain tungsten carbide cutting tool fastened at a $55^{\circ}$ fixed angle of insert. 


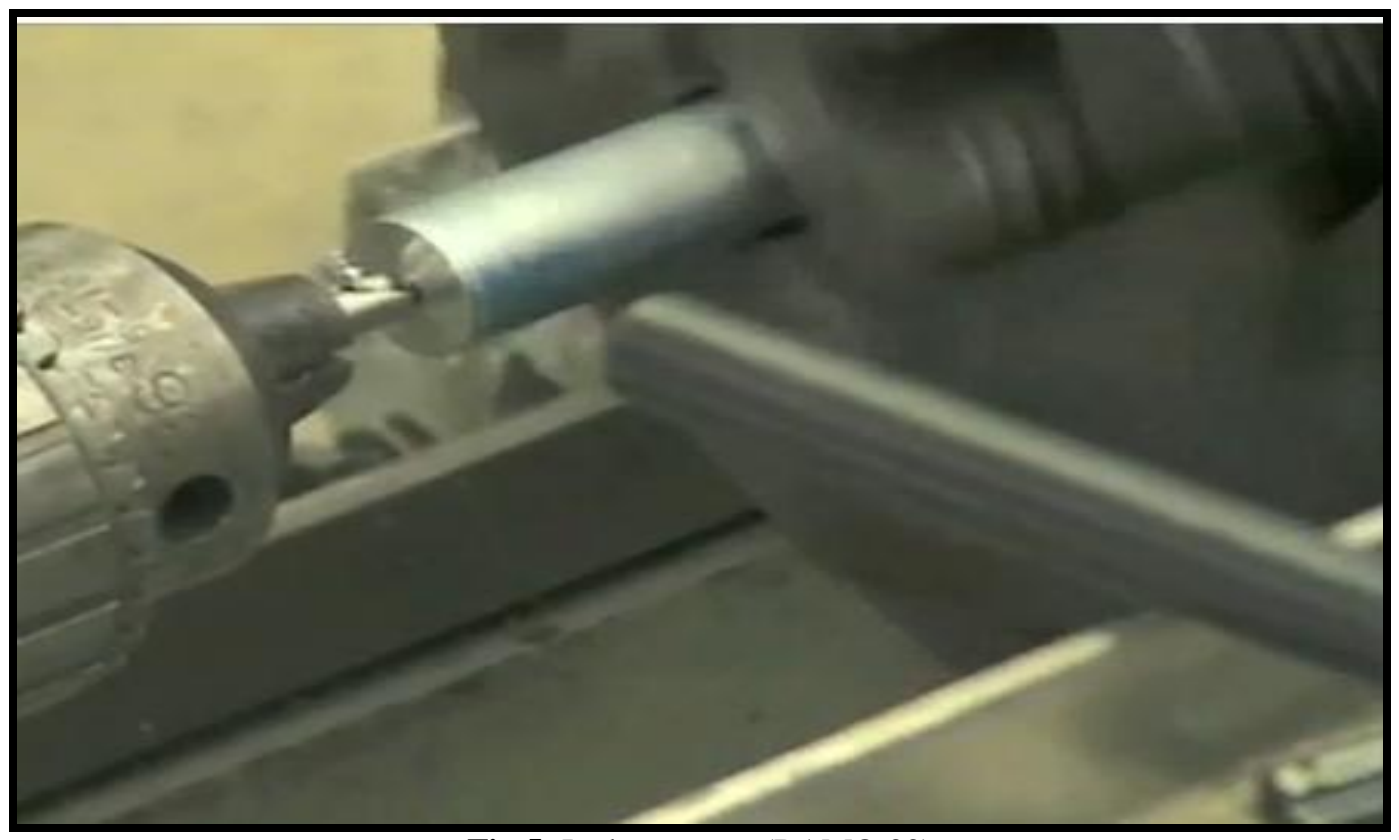

Fig 5: Lathe process (RAMO 33)

The following aggregated heat treatment process on the samples between the ranges of $200^{\circ} \mathrm{C}$ to $600^{\circ} \mathrm{C}$ controls the heating and cooling of the material in order to alter its mechanical properties without physically altering its original dimensions. Subsequently, the specimens were quenched for 1 hour in alternating mediums of water and isorapid oil in order to convert a variety of present microstructures from soft and ductile spheroidite to hard and brittle martensite (Tensi H.M., Stich A., Totten G.E.,1995, Mar).

The samples were finally subjected to different axial tensions and loads until failure using the VEW 2302 (see Figure 6) yielding a variety of mechanical properties from elongation and cross-sectional areas to the determination of values for Young's Modulus, yield strength and strain hardening characteristics.

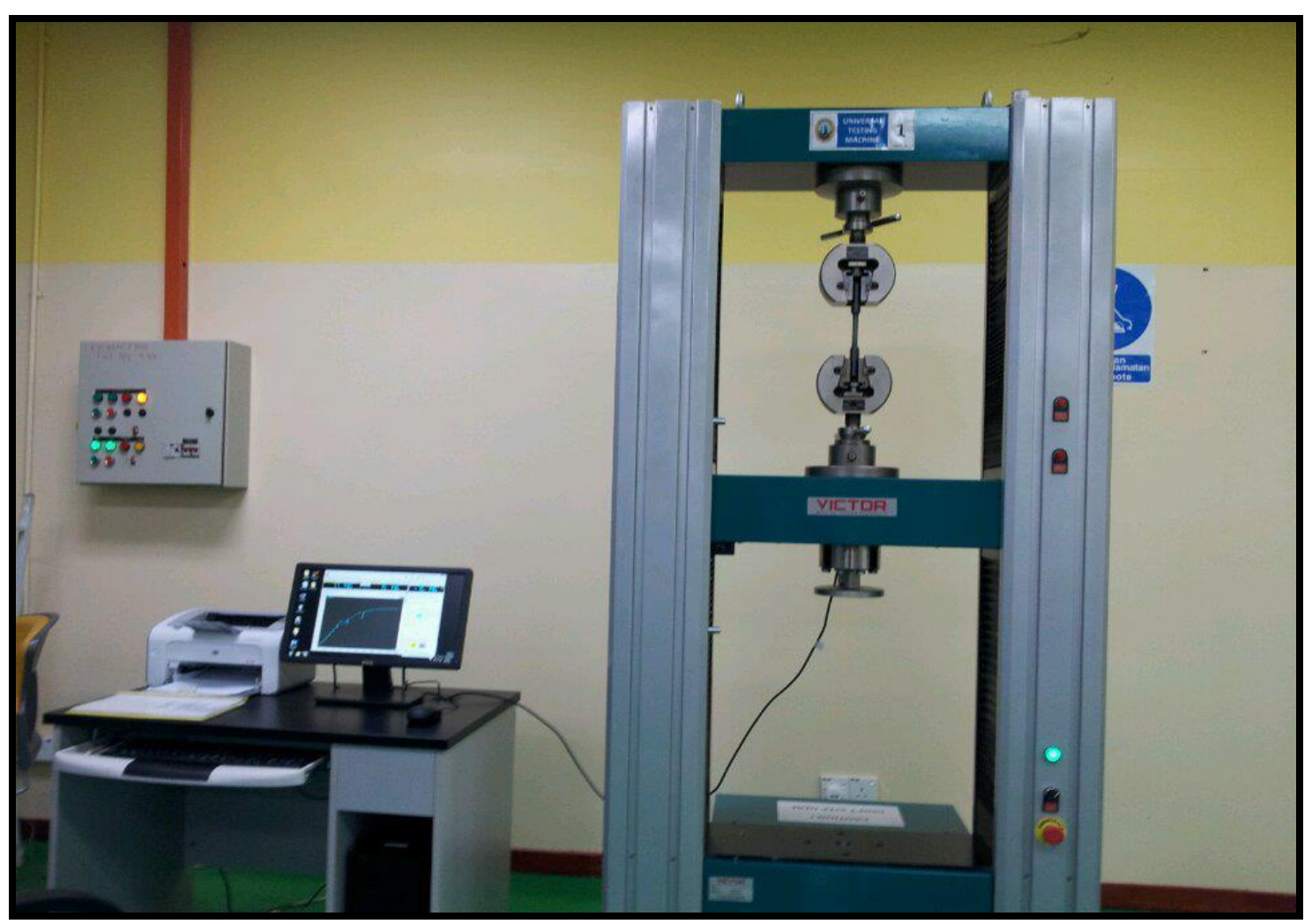

Fig 6: Tensile Test Machine (VEW 2302) 


\section{RESULTS AND DISCUSSION}

The results of the tensile tests performed on the $\mathrm{rod} /$ dumbbell type shaped specimens on medium carbon steel material and quenched using water as a medium is shown in Table 1 below.

Table -1: Results for stress, strain, and percentage elongation (430 RPM \& 860 RPM / Water quenching)

\begin{tabular}{|c|c|c|c|c|c|}
\hline No & $\begin{array}{c}\text { Machining } \\
\text { speed (RPM) }\end{array}$ & $\begin{array}{c}\text { Temp } \\
\left({ }^{0} \mathrm{C}\right)\end{array}$ & $\begin{array}{c}\text { Stress } \\
(\mathrm{MPa})\end{array}$ & $\begin{array}{c}\text { Strain } \\
(\%)\end{array}$ & $\begin{array}{c}\% \\
\text { Elongation }\end{array}$ \\
\hline 1 & $430 \& 860$ & 200 & 637 & 31.050 & 10.364 \\
\hline 2 & $430 \& 860$ & 300 & 596 & 28.850 & 9.2285 \\
\hline 3 & $430 \& 860$ & 400 & 599 & 28.525 & 9.8005 \\
\hline 4 & $430 \& 860$ & 500 & 673 & 27.220 & 8.9875 \\
\hline 5 & $430 \& 860$ & 600 & 657 & 30.100 & 10.467 \\
\hline
\end{tabular}

It is important to note that the lathe machining speeds were alternated between 430 RPM and 860 RPM respectively for each of the 2 sets ( 5 samples per set) to investigate for the occurrences of data variations between the observed parameters of maximum loading (before failure) for stress, strain, and percentage elongation so as to warrant any documentation. However, there were inconsequential differences to the recorded data when machining speeds were indeed varied and were therefore not reflected in the data shown in Table 1 and Table 2.

That allowed for the blanket hypothesis that varied lathe machining speed has no adverse or significant effect on the samples used for tensile testing in the experiment. Therefore, focus would primarily be on the varied temperatures and mediums used in the heat treatment process that did in fact yield significant variations for further deliberations.

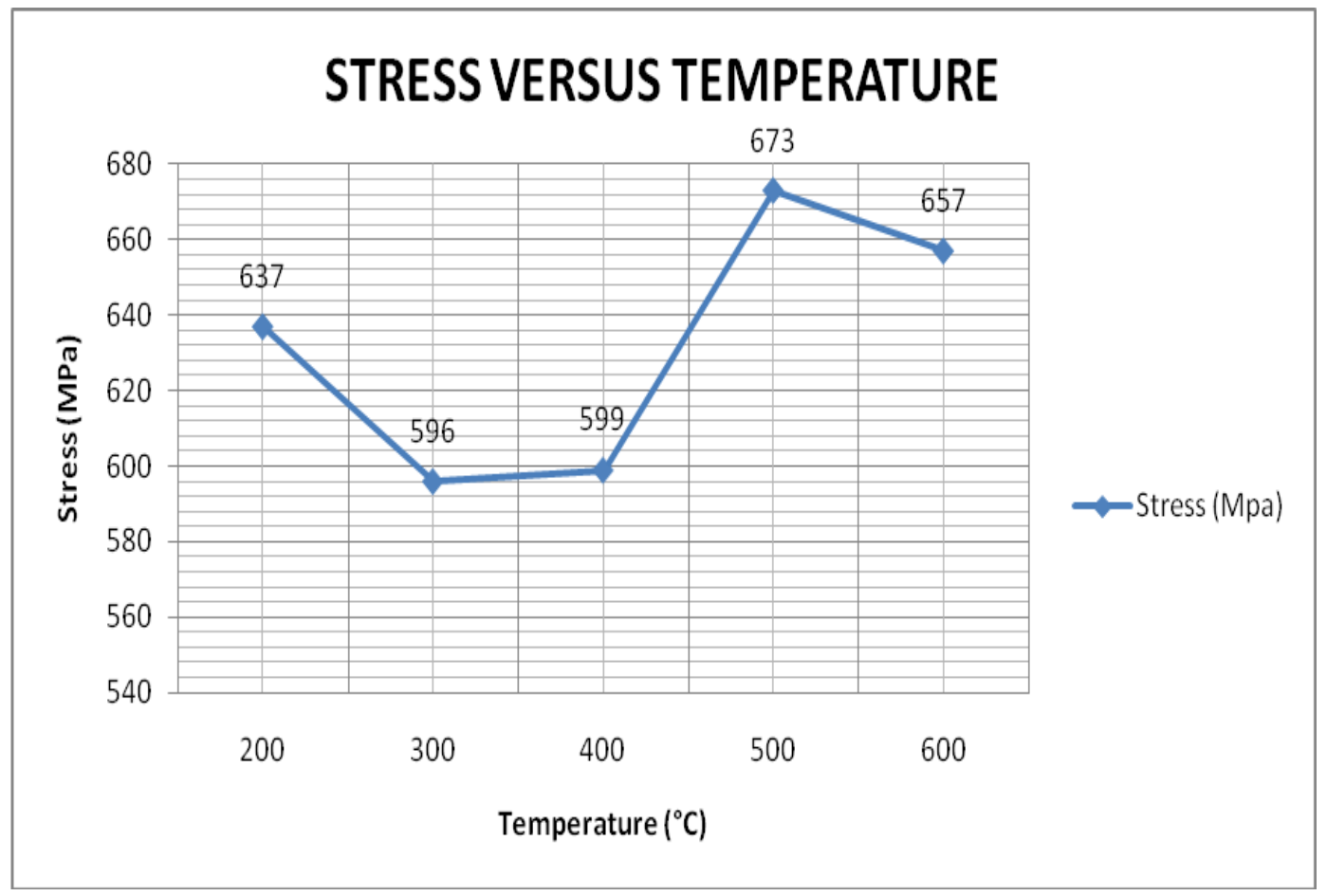

Fig 7

In Figure 7 it can be seen that as temperature increases between 200 to $300^{\circ} \mathrm{C}$, the stress values indicates an inverse relationship for the material. The drop in stress was $41 \%$ while marginally increasing by $0.05 \%$ until $400^{\circ} \mathrm{C}$. Following that, the increase in stress was $12.4 \%$ to $500^{\circ} \mathrm{C}$, and reduced linearly by $2.4 \%$ to $600^{\circ} \mathrm{C}$ until fracture. These linear relationship variations may give rise to the assumption that the effect of quenching in water only allows for stress to increase significantly from 400 to $500^{\circ} \mathrm{C}$, and thereby reducing once reaching that limit as referenced in the sampled specimen material. 


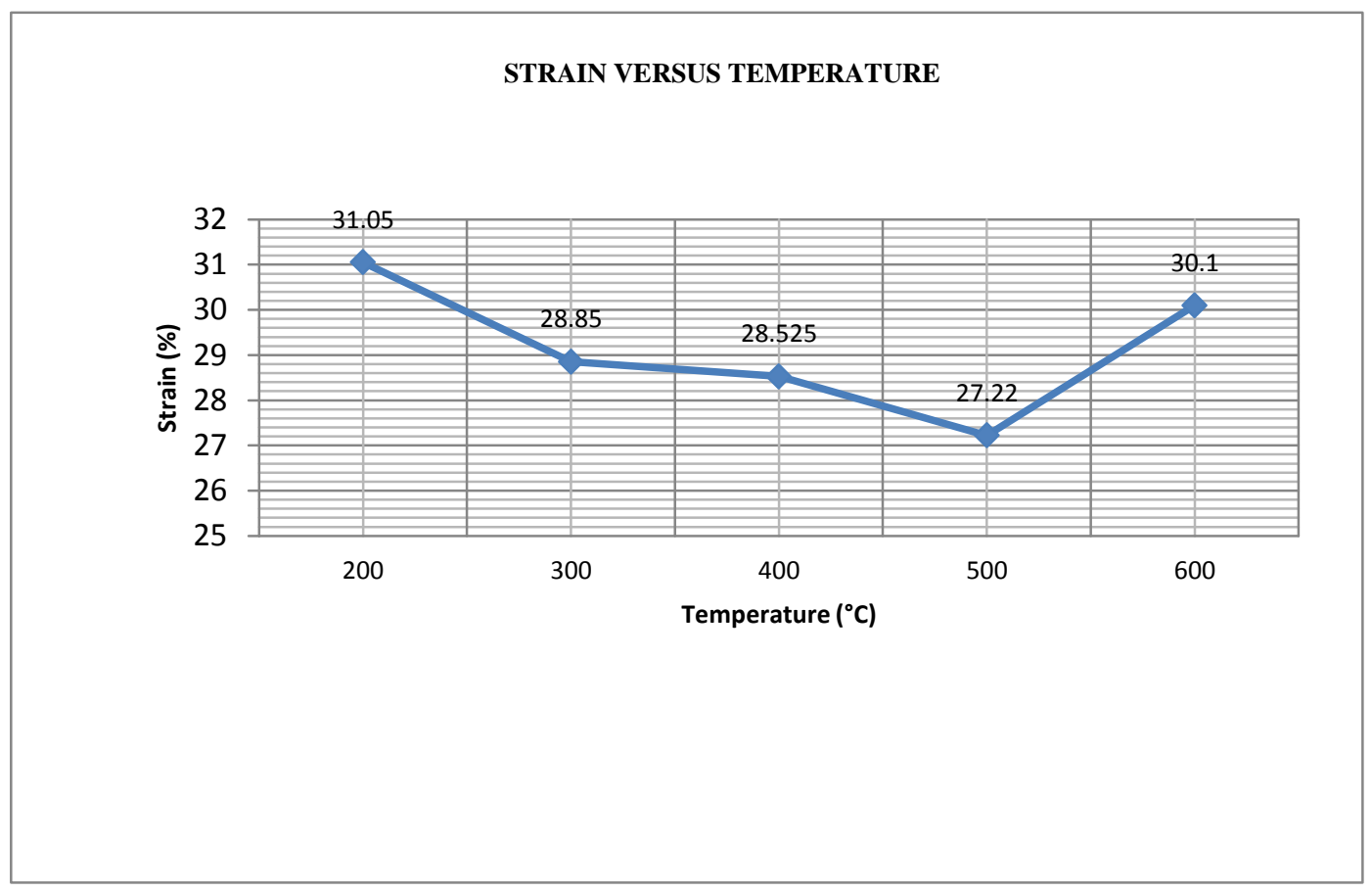

Fig 8

In Figure 8, the strain follows a steady linear value decline of $3.83 \%$ from $200-500{ }^{\circ} \mathrm{C}$ and in stark contrast increases linearly by $2.88 \%$ from $500-600^{\circ} \mathrm{C}$. Thus, the temperature increase from $200^{\circ} \mathrm{C}$ onwards reduces the stain in the material for an aggregated $300^{\circ} \mathrm{C}$ block increase only.

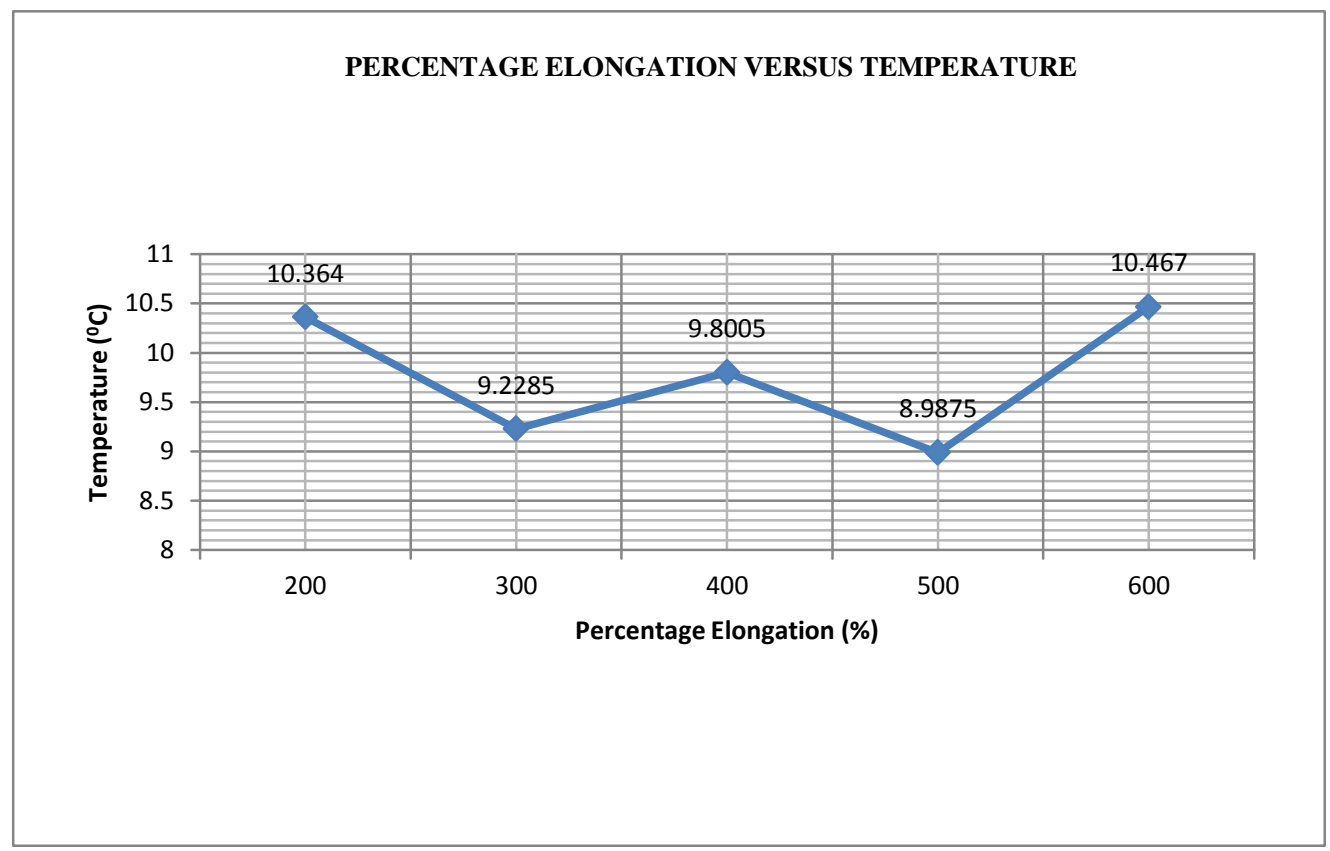

Fig 9

A jagged linear relationship is shown in Figure 9 for the percentage elongation experienced by the specimen sample material after quenching indicating a disproportionate relationship of linear and inversely linear correlations for aggregated temperature increases of $100^{\circ} \mathrm{C}$. For example, from $200-300^{\circ} \mathrm{C}$, there is a $1.14 \%$ decrease that is approximately mirrored by the quantum of $0.813 \%$ in the $400-500^{\circ} \mathrm{C}$ range. However, a linear increase of $0.57 \%$ and
$1.48 \%$ can be seen in the $300-400^{\circ} \mathrm{C}$ and $500-600^{\circ} \mathrm{C}$ range. For the $400-600^{\circ} \mathrm{C}$ range, the averaged fluctuation is $1.15 \%$. Therefore, a conclusive linear correlation may not necessarily exist in terms of the recorded percentage elongation data for the material.

The results of the tensile tests performed on the specimens on medium carbon steel material and quenched using 
isorapid oil as a medium for quenching is shown in Table 2 below.

Table -2: Results for stress, strain, and percentage elongation (430 RPM \& 860 RPM / Oil quenching)

\begin{tabular}{|c|c|c|c|c|c|}
\hline No & $\begin{array}{c}\text { Machining } \\
\text { speed (RPM) }\end{array}$ & $\begin{array}{c}\text { Temp } \\
\left({ }^{0} \mathrm{C}\right)\end{array}$ & $\begin{array}{c}\text { Stress } \\
(\mathrm{MPa})\end{array}$ & $\begin{array}{c}\text { Strain } \\
(\%)\end{array}$ & $\begin{array}{c}\% \\
\text { Elongation }\end{array}$ \\
\hline 1 & $430 \& 860$ & 200 & 653 & 27.890 & 8.993 \\
\hline 2 & $430 \& 860$ & 300 & 654 & 28.150 & 9.728 \\
\hline 3 & $430 \& 860$ & 400 & 639 & 29.650 & 10.305 \\
\hline 4 & $430 \& 860$ & 500 & 524 & 19.880 & 7.562 \\
\hline 5 & $430 \& 860$ & 600 & 634 & 29.120 & 10.333 \\
\hline
\end{tabular}

In Figure 10, the almost horizontal correlation between stress and temperature increase due to quenching in isorapid oil gives the hypothetical assumption that the medium used does not adversely influence the mechanical material properties of the sample specimen.

The only noticeable decrease in stress was at $500^{\circ} \mathrm{C}$, which may also not be significant should the sample frequency be increased in later trials.

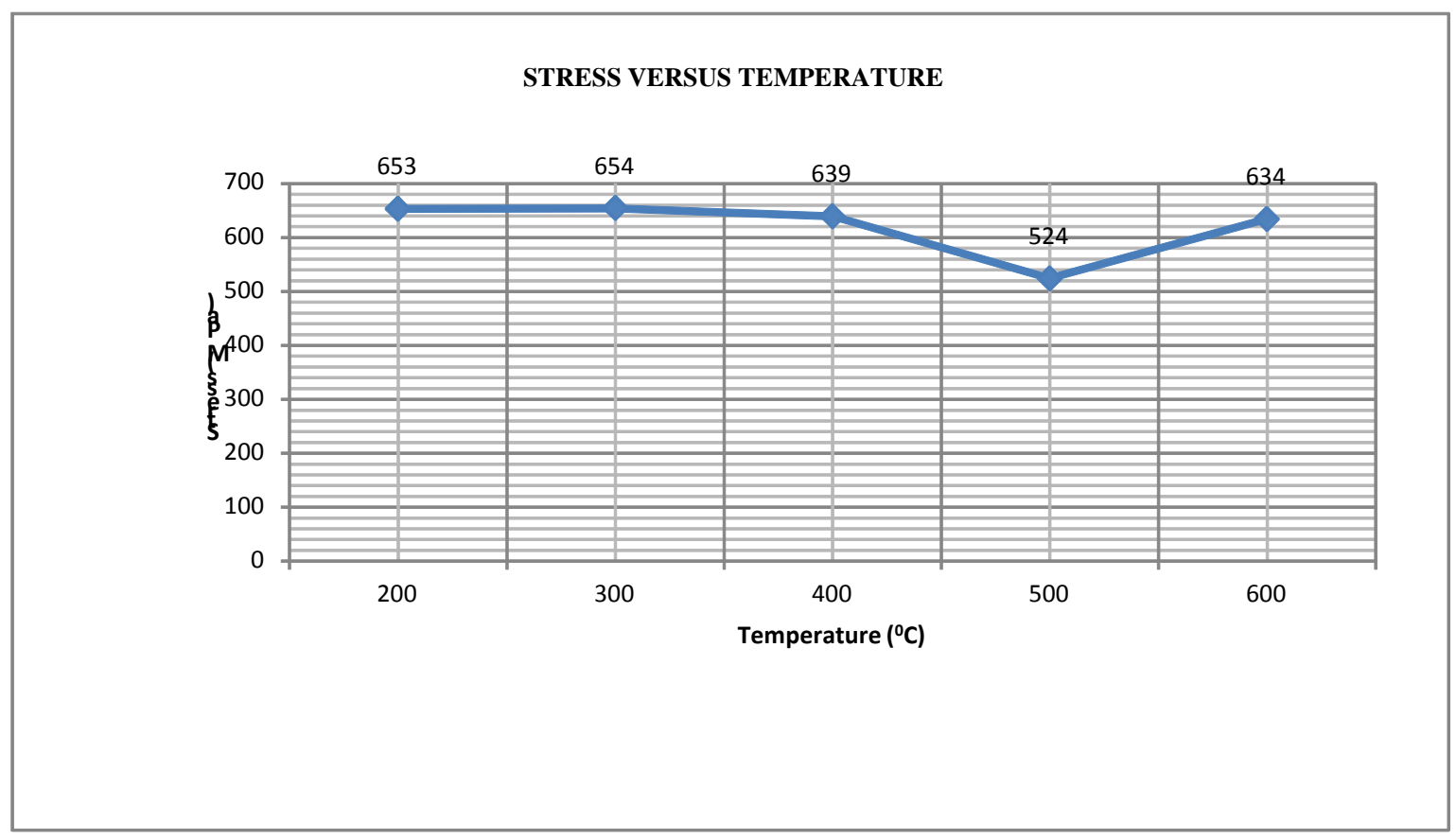

Fig 10

In Figure 11, a similar reoccurrence of a horizontal relationship between strain and temperature can be noticed. As with the relationship with stress, the increase in strain due to temperature change after isorapid oil quenching yields stain values in the range of $27.5-29.5 \%$ only for a $400^{\circ} \mathrm{C}$ block of temperature fluctuation.

As such, it may not be premature to assume that the selected medium of quenching (isorapid oil) does not adversely influence the mechanical material properties of the sample specimen. Once again, the only noticeable decrease in strain was at $500^{\circ} \mathrm{C}($ as mentioned earlier, may also not be significant should the sample frequency be increased in later trials). 


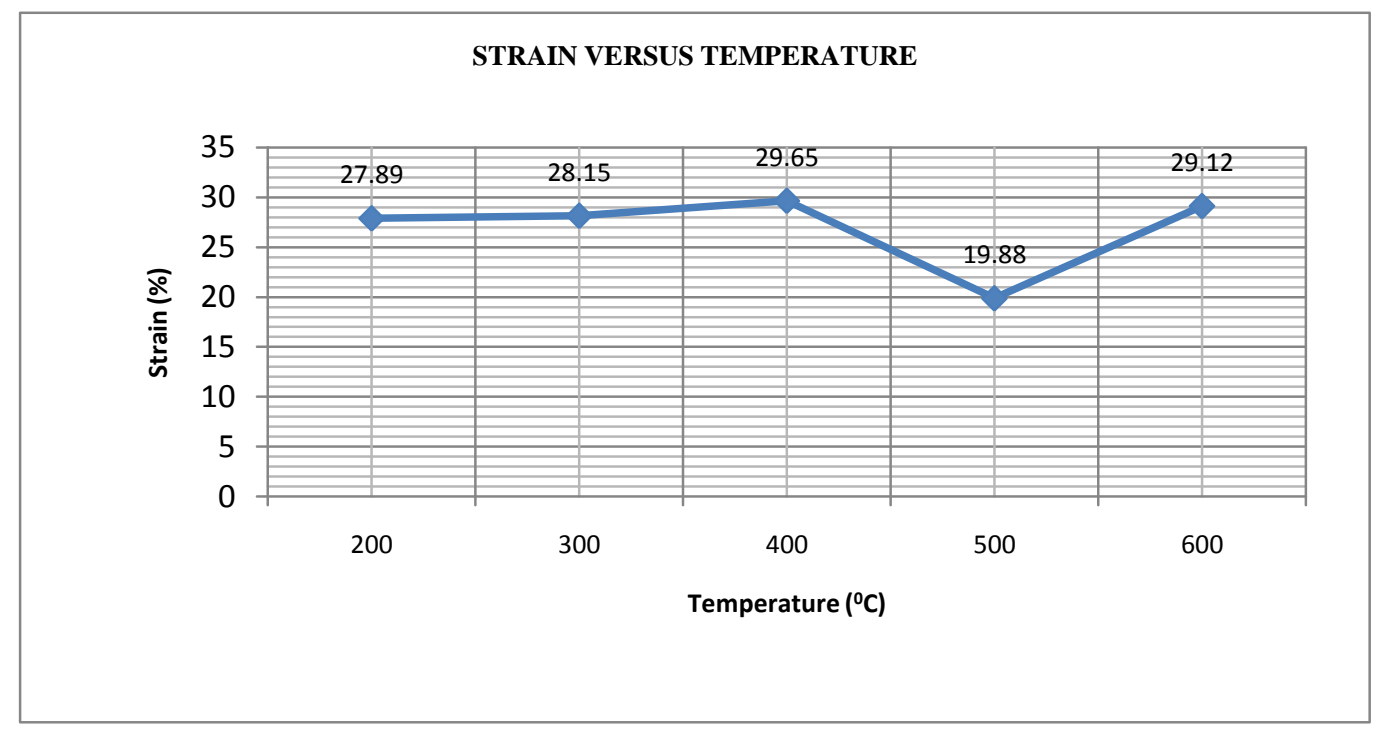

Fig 11

In Figure 12, a minor fluctuation in percentage elongation can be seen for quenching in isorapid oil over the $200-600^{\circ} \mathrm{C}$ temperature range. In relative comparison to Figure 9 (quenching in water), the jagged linear relationship is only apparent at $400^{\circ} \mathrm{C}$.

The relationship remains mainly horizontal in nature from $200-400^{\circ} \mathrm{C}$ with a $1.31 \%$ fluctuation, and the averaged higher jagged increase (and decrease) of approximately $2.75 \%$ is significantly higher than the $1.15 \%$ average fluctuation noticed for water.

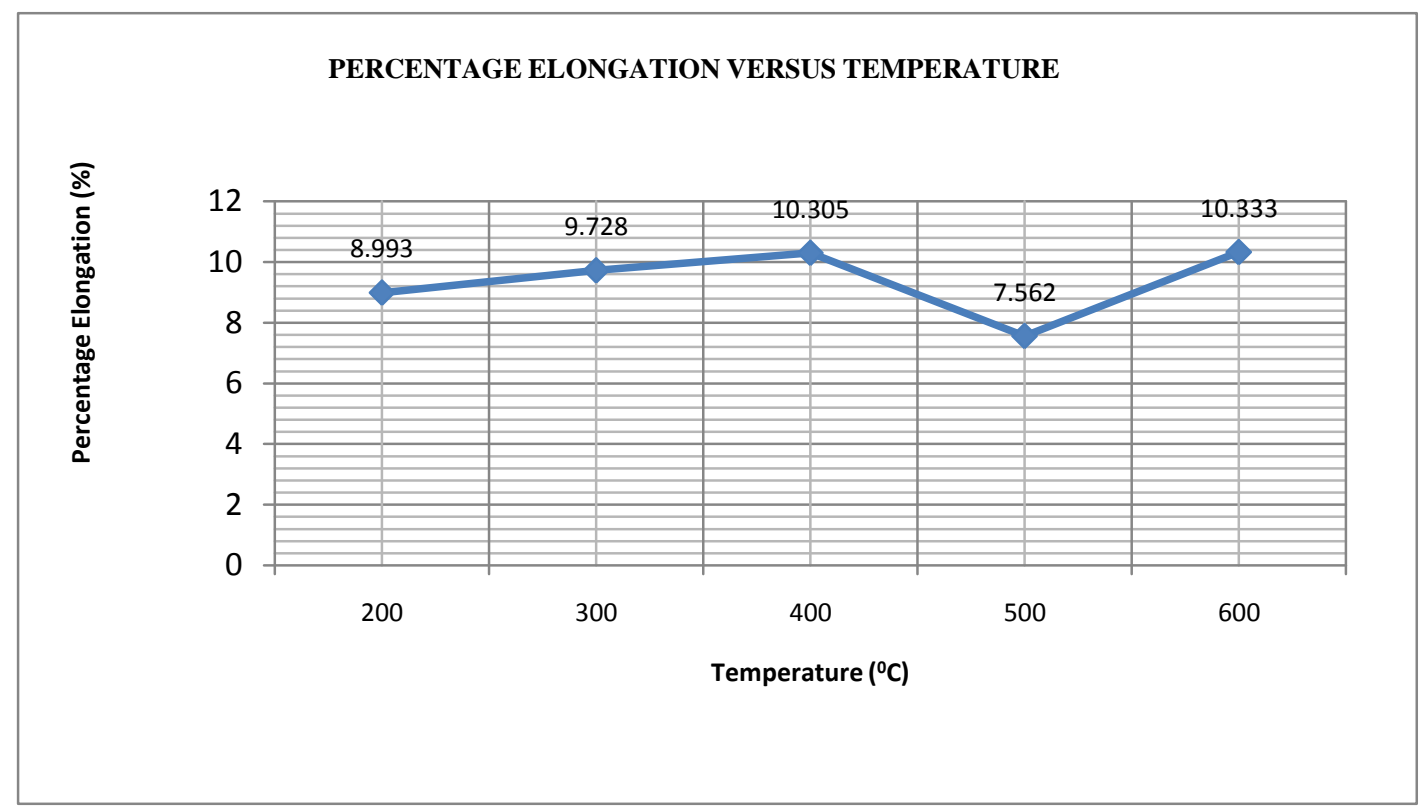

Fig 12

\section{CONCLUSION}

In the experiment, a study into the factors affecting the tensile material strength of specimens fabricated under specific lathe machining conditions was successfully undertaken and completed. The results indicate that a change in machining speed (430 to 860 RPM) does not influence the mechanical properties of medium carbon steel in any way since no significant incremental changes were noticed in any of the data recorded. However, noticeable fluctuation in stress, strain and percentage elongation of the material specimen were apparent over the $200-600^{\circ} \mathrm{C}$ temperature range in both water and isorapid oil that were selected as the mediums of quenching after the heat treatment process. However, a more substantial change in these measured mechanical properties was recorded for the sample material quenched in water as compared to isorapid oil. That leads to the conclusion that heat treatment and quenching in water can be more effective in material hardening and thus significantly affecting its mechanical properties for future analysis and application. 


\section{REFERENCES}

[1] Smith and Hashemi "Foundations of Materials Science and Engineering", Propriety Material (C) ,2006 The McGraw-Hill Companies, lnc.

[2] R.R. Blackwood and W.D. Cheesman, "Metal Quenching Medium", U.S. Patent, 3,220,893, November 30, 1996.

[3] G.E. Totten and G.M. Webster, "Effect of Section Size, Quenchant Concentration and Agitation on The Physical Properties of Type i- Polymer Quenched Aluminum Alloys, Union Carbide Corporation Tarrytown, NY, February 24, 2000.

[4] Jamiu Kolawole Odusote, Tajudeen Kolawole Ajiboye and Abdulkarim Baba Rabiu, "Evaluation of Mechanical Properties of Medium Carbon Steel Quenched in Water and Oil", Department of Metallurgy and Material Engineering, University of Ilorin, AU J.T. 15(4): 218-224 (Apr. 2012).

[5] T. Senthilkumar and T. K. Ajiboye, "Effect of Heat Treatment Processes on the Mechanical Properties of Medium Carbon Steel", Journal of Minerals \& Materials Characterization \& Engineering, Vol. 11, No.2 pp.143-152, 2012 jmmce.org, May 2012.

[6] Anselmo Eduardo Diniz and Álisson Rocha Machado,"Application of Cutting Fluids in Machining Processes", 2001.

[7] M. B. Ndaliman, "An Assessment of Mechanical Properties of Medium Carbon Steel under Different Quenching Media”, AU J.T. 10(2): 100-104 (Oct. 2006).

[8] Anand B. Desspande, "Characretistic in Mechanical Propeties for Medium Carbon Steel", November 2010.

[9] Tensi H.M., Stich A., Totten G.E., "Fundamentals of Quenching, Metal HeatTreating", 1995, Mar./Apr., p. 20-28. 